Research Article

\title{
Study of Strength and Deformation Evolution in Raw and Briquette Coal Samples under Uniaxial Compression via Monitoring Their Acoustic Emission Characteristics
}

\author{
Han Meng ${ }^{D}$, Yuzhong Yang ${ }^{(D)}$, Liyun Wu, Fei Wang, and Lei Peng \\ School of Energy Science and Engineering, Henan Polytechnic University, Jiaozuo 454003, Henan, China \\ Correspondence should be addressed to Yuzhong Yang; jityyz@hpu.edu.cn
}

Received 30 June 2020; Revised 1 September 2020; Accepted 19 October 2020; Published 31 October 2020

Academic Editor: Chunshun Zhang

Copyright @ 2020 Han Meng et al. This is an open access article distributed under the Creative Commons Attribution License, which permits unrestricted use, distribution, and reproduction in any medium, provided the original work is properly cited.

\begin{abstract}
Briquette coals with different cement contents are frequently used to study the coal body's properties. In this study, the deformation and strength of briquette coal samples with $0,5,10$, and $20 \%$ cement contents were experimentally and theoretically investigated using the acoustic emission (AE) characteristics monitored during the uniaxial compression tests. The results show that the uniaxial compression process of raw coal and briquette coal samples can be subdivided into compaction, elastic, plastic (yield), and brittle failure stages. With an increase in cement content, briquette coal samples undergo the elastic and plastic stages, and their postpeak stress drop rate gradually grows, and their plastic deformation is followed by brittle failure. The uniaxial compressive strength and elastic modulus of briquette coal samples show a linearly increasing relationship with cement content, while their Poisson's ratio decreases gradually. During the uniaxial compression, raw coal and briquette coal samples produce the AE signals. The overall AE signal of briquette coal samples is relatively low, and there are no obvious AE events in raw coal samples. The uniaxial compressive strength, elastic modulus, and Poisson's ratio of briquette coal samples with a $20 \%$ cement content and their AE signal cumulative amplitude, count, and energy values are very close to the corresponding parameters of raw coal samples. Therefore, they can be used for simulating raw coal samples in laboratory tests.
\end{abstract}

\section{Introduction}

Coal production is jeopardized by coal and gas outbursts, with a large amount of gas and coal and rock mass sprayed out from the outburst mouth, which often results in serious casualties and huge economic losses $[1,2]$. To prevent coal and gas outbursts accidents, the mechanism of coal and gas outbursts has been extensively studied, and a series of related theories and hypotheses have been proposed [3]. Most scholars share the synthetic concept of coal and gas outburst, which implies that the outburst is determined by the in-situ stress, gas pressure, and physical and mechanical properties of the coal body $[4,5]$. Therefore, it is crucial to study the mechanical properties of coal to reveal the mechanism of coal and gas outbursts. When conducting mechanical tests on coal and rock bodies in the laboratory, AE sounds are often produced. Therefore, the mechanical tests of coal bodies can analyze the strength and deformation characteristics of the coal body and the AE characteristics during fracture. The acoustic emission (AE) technology, as a nondestructive evaluation method, is often used to study rock material instability, cracking, and evolution $[6,7]$. Through the analysis of AE signals of coal and rock masses, it is possible to deduce the internal morphological changes in coal and rock masses, and then to identify the fracture mechanism and degree of fracture of coal and rock masses, to predict the dynamic disasters of coal and rock masses $[8,9]$.

The mechanical properties and AE characteristics of coal and rock bodies have been studied by numerous researchers. Masahiro et al. [10] studied the source distribution of AE in coal samples under uniaxial compression and reported that the $\mathrm{AE}$ sources were distributed along the cracks in a band. Masurov [11] and Rudajev et al. [10] used AE monitoring to 
measure rock damage and predict the type of rock failure. Shkuratnik [12] studied the AE characteristics of coal samples under uniaxial compression at various loading rates. Wang et al. [13] studied the characteristics of the AE spectrum generated during the fracture of raw coal samples under uniaxial compression. Yang et al. [14] investigated the AE characteristics of raw coal samples under uniaxial compression and concluded that the fracture of coal rock masses could be predicted by the AE monitoring results. Cao et al. [15] performed AE tests on outburst raw coal samples under uniaxial compression and creep conditions. The results showed that the outburst raw coal samples had significantly different $\mathrm{AE}$ characteristics from homogeneous rocks such as sandstone. Ranjith et al [16] used AE to record the strain energy release rate of Australian black coal samples under uniaxial compression after carbon dioxide saturation. Su et al. [17] conducted uniaxial compression tests on raw coal samples of two scales with the AE monitoring and concluded that it is more reasonable to predict the coal and rock dynamic disasters using the AE characteristic values of large raw coal samples. Huang et al [18] studied the AE parameters of composite coal samples during rapid loading and unloading to assess the composite coal rock mining process's hazards. Perera et al [19] conducted comprehensive unconfined compressive strength tests on Australian black coal and lignite coal samples and identified the crack propagation behavior using AE devices. Dong et al. [20] analyzed the AE response of different waveguides in coal rock to predict the dynamic coal rock disaster conditions. In the research of adding cement to briquette, Jasinge et al. [21, 22] found that the closest match for the natural coal samples were reconstituted coal samples with a $4 \%$ cement content and $50 \%$ water content.

Most of the above uniaxial tests on coal and rock masses with AE monitoring were conducted using raw coal samples without comparative studies of briquette coal samples. However, the coal body texture in most mines in China is relatively loose, and the bedding and joints are well developed. The core sampling success rate of raw coal samples during their preparation is relatively low. Moreover, even successfully drilled standard raw coal samples may fail to comprehensively reflect the characteristics of the coal seam under study [23]. At present, many scholars share the notion that although there is a certain difference between raw coal and briquette coal samples, their physical and mechanical properties are very similar. Therefore, many studies on the mechanics of coal seams and their permeability characteristics use the briquette coal samples $[24,25]$. In this paper, cement is used as a binder mixed with crushed pulverized coal to form coal samples. Then, uniaxial compression and $\mathrm{AE}$ tests are carried out on raw coal and briquette coal samples with different cement contents, monitoring the uniaxial compression deformation and $\mathrm{AE}$ characteristics.

The research is aimed to identify briquette coal samples of a proper cement content with the mechanical properties and $\mathrm{AE}$ characteristics close to those of the raw coal, through uniaxial compression tests. This finding is considered instrumental in the follow-up coal and gas outburst tests in the laboratory using briquette coal samples and seepage mechanics studies of low-permeability coal seams.

\section{Coal Sample Characteristics and Test Methods}

2.1. Preparation of Raw Coal Samples. The coal samples were acquired from the 11110 fully mechanized coal mining face of No.13 Coal Mine of the Pingdingshan Tian'an Coal Industry Co., Ltd., located in Xiangcheng County, Xuchang, Henan Province of China. The coal samples collected in the mining face were wrapped in plastic film and transported to the laboratory. The coal core was drilled by parallel bedding in the laboratory, and then cut and smoothed into standard coal samples with a height of $100 \mathrm{~mm}$ and a diameter of $50 \mathrm{~mm}$. The accuracy of the processed samples met the regulation requirements [26]. A total of 40 standard coal samples were processed, with an apparent natural density ranging between 1305 and $1448 \mathrm{~kg} / \mathrm{m}^{3}$ (with an average value of $1374 \mathrm{~kg} / \mathrm{m}^{3}$ ) and longitudinal wave velocity distribution between 1269 and $2032 \mathrm{~m} / \mathrm{s}$ (with an average value of $1672 \mathrm{~m} / \mathrm{s}$ ). The variation of the above properties indicates that the coal sample body has a certain dispersion related to the heterogeneity of the coal sample body. Figure 1 depicts raw coal samples.

2.2. Preparation of Briquette Coal Samples. The raw coal used for briquette coal preparation was also acquired from the above mining face and transported to the laboratory in plastic sacks. The jaw plate crusher was used to break the coal blocks remaining after raw coal drilling, and the crushed coal body was sieved. Coal powder particles with size from 0.18 to $0.25 \mathrm{~mm}$ were selected as raw materials for preparing briquette coal samples.

The 42.5 grade ordinary Portland cement was used as the binder for preparing briquette coal samples due to its excellent hydration, hardening, and impermeability properties $[27,28]$. A certain proportion of cement and water was added to the coal powder with a particle size of 0.18 to $0.25 \mathrm{~mm}$; the mixture was stirred, placed into the mold, and stabilized at a molding pressure of $100 \mathrm{MPa}$ applied by a $200 t$ material-testing machine for $30 \mathrm{~min}$. The standard briquette coal sample had a height of $100 \mathrm{~mm}$ and a diameter of $50 \mathrm{~mm}$.

The pulverized coal-cement-water ratios of briquette coal samples used in this paper were as follows: (i) 1.00 : $0.00: 0.05$, (ii) $0.95: 0.05: 0.069$; (iii) $0.90: 0.10: 0.072$; (iv) $0.80: 0.20: 0.083$.

The formed briquette coal samples are placed in a constant temperature and humidity box (temperature of $20^{\circ} \mathrm{C}$ and humidity of $95 \%$ ), cured for 28 days, then placed into an oven $\left(105^{\circ} \mathrm{C}\right)$, and dried for $12 \mathrm{~h}$. After cooling to room temperature, samples were placed into a drying dish for further test use. The prepared briquette coal samples are shown in Figure 2.

2.3. Experimental Setup. Uniaxial compression tests were conducted via an RMT-150B electrohydraulic servo rock test 


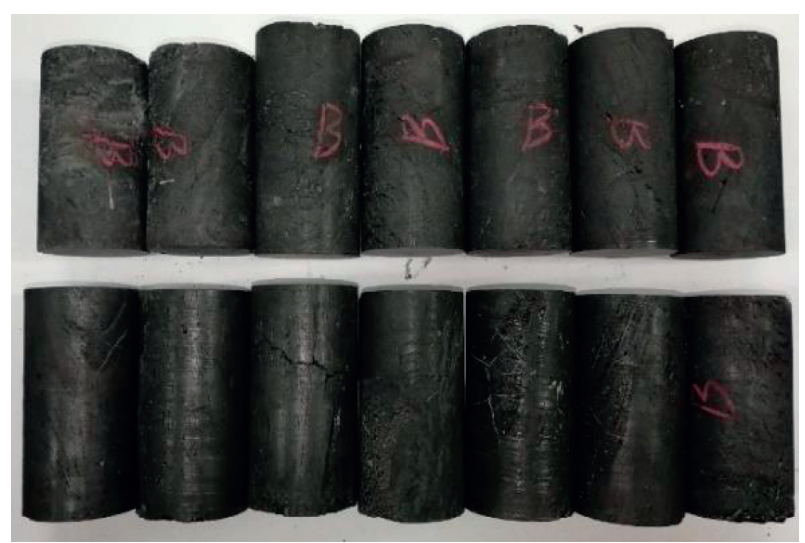

FIGURE 1: Raw coal samples.

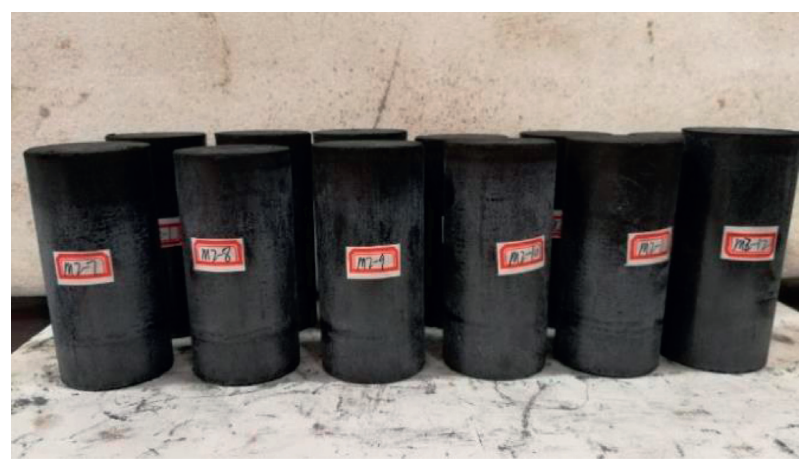

Figure 2: Briquette coal samples.

system, as shown in Figure 3. The axial load was measured with a $100 \mathrm{kN}$ force sensor, with the load accuracy of $1.0 \times 10^{-3} \mathrm{kN}$. The axial and circumferential strains were measured with $5.0 \mathrm{~mm}$ and $2.5 \mathrm{~mm}$ displacement sensors, respectively, with the displacement accuracy of $1.0 \times 10^{-3} \mathrm{~mm}$. The test used displacement control, with a loading rate of $0.005 \mathrm{~mm} / \mathrm{s}$. During the mechanical loading of coal samples, a DS-5 type 8-channel AE system was used for the online AE monitoring. The AE sensor was installed in the middle of the coal sample and fixed with the insulating tape. The sampling frequency was set to $3 \mathrm{MHz}$, the RS-2A AE sensor frequency was $150 \mathrm{kHz}$ with the threshold value for mechanical and ambient noise was set $50 \mathrm{~dB}$. The data acquisition system recorded a series of parameters, such as AE amplitude, count, and energy on a real-time scale.

\section{Test Results and Analysis}

3.1. Deformation Characteristics. Table 1 lists the uniaxial compression AE test results of raw coal and briquette coal samples with different cement contents. In Table $1, R c, E_{\mathrm{T}}$, and $\mu$ are the uniaxial compressive strength, elastic modulus, and Poisson's ratio of the sample, respectively; $\sum A, \sum N$, and $\sum E$ are the $\mathrm{AE}$ amplitude, count, and accumulated energy accumulation of the AE of the coal sample under uniaxial compression, respectively.

Figure 4 shows the fully stress-strain curves of the raw coal sample and the briquette coal sample with different

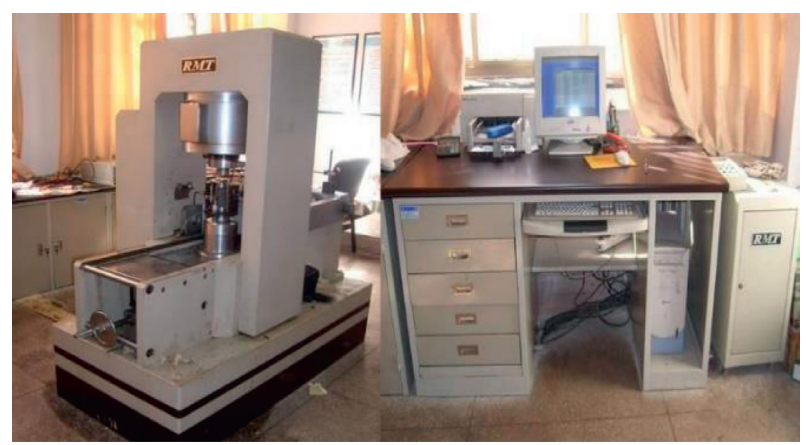

Figure 3: The RMT-150B electrohydraulic servo rock test system.

cement contents in the uniaxial compression test. It can be seen from Figure 4 that the stress-strain curve of coal samples during uniaxial compression can be roughly subdivided into the compaction, elastic, plastic (yield), and failure stages. At the compaction stage, the tangential elastic modulus of the coal sample increases with the axial stress, while pores and microcracks in the coal sample close, and its volume gradually decreases. At the elastic stage, the stressstrain relationship follows Hooke's law. At the plastic (yield) stage, the coal sample stress reaches the yield strength, the material with lower internal strength of the coal sample first appears and develops continuously, and the stress-strain curve deviates from the straight line. This is the initial damage development process of the coal sample. At the final (failure) stage, the coal sample's axial stress reaches its ultimate capacity. The macroslip occurs along a fracture surface inside the coal sample, and the tensile stress is generated longitudinally in the coal sample under the initial friction. The rapid drop in stress causes the coal sample to lose its overall stability.

The average uniaxial compressive strength of raw coal samples is $4.34 \mathrm{MPa}$, the average elastic modulus is $1.47 \mathrm{GPa}$, and the average Poisson's ratio is 0.19 . It can be seen in Figure 4(a) that the failure of raw coal samples (especially, MB6 and MB7) is brittle, which manifests itself by the instantaneous drop of stress, while the raw coal samples MB3 and MB4 show a stepped drop. However, from the uniaxial compression stress-strain curve of raw coal samples, it can be found that their mechanical characteristics are more discrete, which is related to the nature of the coal body. The coal body itself has pores, cracks, and coal seam joint development, while other factors directly affect the mechanical characteristics of the coal body.

Compared with raw coal samples, the axial strains of briquette coal samples with cement contents of $0,5,10$, and $20 \%$ are larger, as shown in Figures $4(\mathrm{~b})-4(\mathrm{e})$. The stressstrain curves of coal samples with different cement contents under uniaxial compression indicate that the cement content mainly affects the curve's elastic and plastic stages. Compared with Figure 4(a), the elastic and plastic stages of briquette coal samples from group I during uniaxial compression are more obvious. The briquette coal samples MS9 and MS10 have a stress drop, while MS8 has a relatively lowstress drop, as is shown in Figure 4(b). The uniaxial compression stress-strain curves of briquette coal samples from 
TABLE 1: Test results on coal sample uniaxial compression.

\begin{tabular}{|c|c|c|c|c|c|c|c|}
\hline Coal sample type & Designation & $R \mathrm{c} / \mathrm{MPa}$ & $E_{\mathrm{T}} / \mathrm{GPa}$ & $\mu$ & $\sum A / \mathrm{x} 10^{6}$ & $\sum N / \mathrm{x} 10^{5}$ & $\sum E / \times 10^{5}$ \\
\hline \multirow{7}{*}{ Raw coal samples } & MB1 & 4.82 & 1.49 & 0.22 & 2.01 & 7.69 & 9.07 \\
\hline & MB3 & 6.23 & 1.70 & 0.21 & 1.52 & 4.88 & 6.16 \\
\hline & MB4 & 2.36 & 0.91 & 0.20 & 1.53 & 4.11 & 4.73 \\
\hline & MB6 & 3.93 & 1.74 & 0.22 & 0.97 & 1.54 & 1.97 \\
\hline & MB7 & 3.94 & 1.37 & 0.22 & 2.72 & 6.82 & 11.86 \\
\hline & MH3 & 4.76 & 1.60 & 0.09 & 0.47 & 3.38 & 3.53 \\
\hline & Average & 4.34 & 1.47 & 0.19 & 1.54 & 4.74 & 6.22 \\
\hline \multirow{4}{*}{ Briquette coal samples with a $0 \%$ cement content } & MS8 & 1.38 & 0.12 & 0.24 & 1.60 & 0.62 & 0.58 \\
\hline & MS9 & 1.53 & 0.13 & 0.34 & 3.85 & 1.30 & 1.56 \\
\hline & MS10 & 1.58 & 0.12 & 0.22 & 1.32 & 0.68 & 0.49 \\
\hline & Average & 1.50 & 0.12 & 0.27 & 2.26 & 0.87 & 0.88 \\
\hline \multirow{4}{*}{ Briquette coal samples with a $5 \%$ cement content } & M2-2 & 2.77 & 0.23 & 0.12 & 3.36 & 1.41 & 1.54 \\
\hline & M2-3 & 3.11 & 0.25 & 0.16 & 3.10 & 1.21 & 1.23 \\
\hline & M2-4 & 3.28 & 0.28 & 0.19 & 3.69 & 1.43 & 1.35 \\
\hline & Average & 3.05 & 0.25 & 0.16 & 3.38 & 1.35 & 1.37 \\
\hline \multirow{4}{*}{ Briquette coal samples with a $10 \%$ cement content } & M3-1 & 3.31 & 0.29 & 0.08 & 3.70 & 1.45 & 1.80 \\
\hline & M3-2 & 3.30 & 0.28 & 0.11 & 3.70 & 1.45 & 1.80 \\
\hline & M3-3 & 3.45 & 0.28 & 0.11 & 4.50 & 1.46 & 2.06 \\
\hline & Average & 3.35 & 0.28 & 0.10 & 3.97 & 1.45 & 1.89 \\
\hline \multirow{4}{*}{ Briquette coal samples with a $20 \%$ cement content } & M4-1 & 4.76 & 0.45 & 0.13 & 5.30 & 1.76 & 3.43 \\
\hline & M4-2 & 4.57 & 0.48 & 0.11 & 4.54 & 1.46 & 2.60 \\
\hline & M4-3 & 5.13 & 0.54 & 0.08 & 4.07 & 1.35 & 2.19 \\
\hline & Average & 4.82 & 0.49 & 0.11 & 4.64 & 1.52 & 2.74 \\
\hline
\end{tabular}

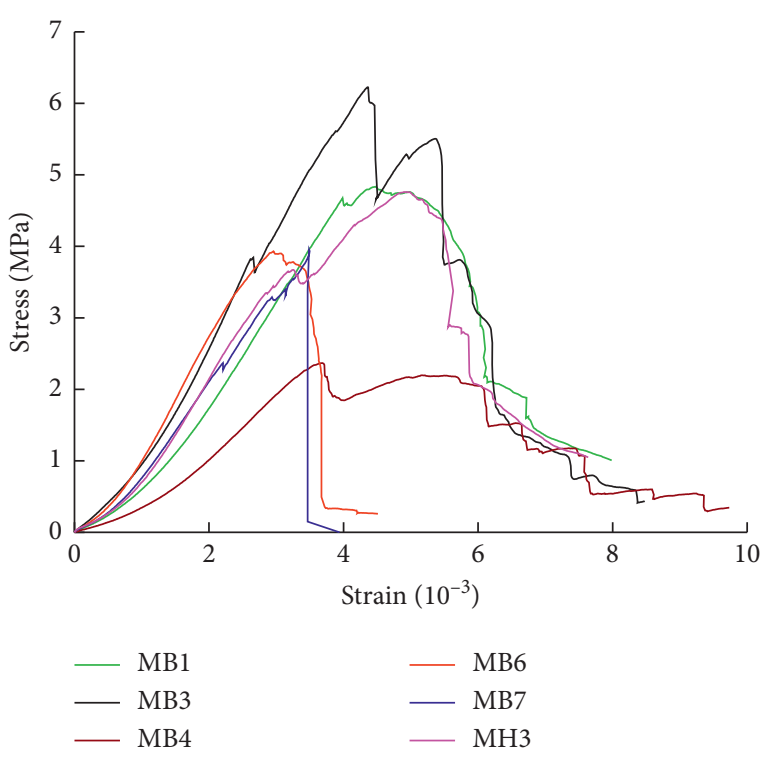

(a)

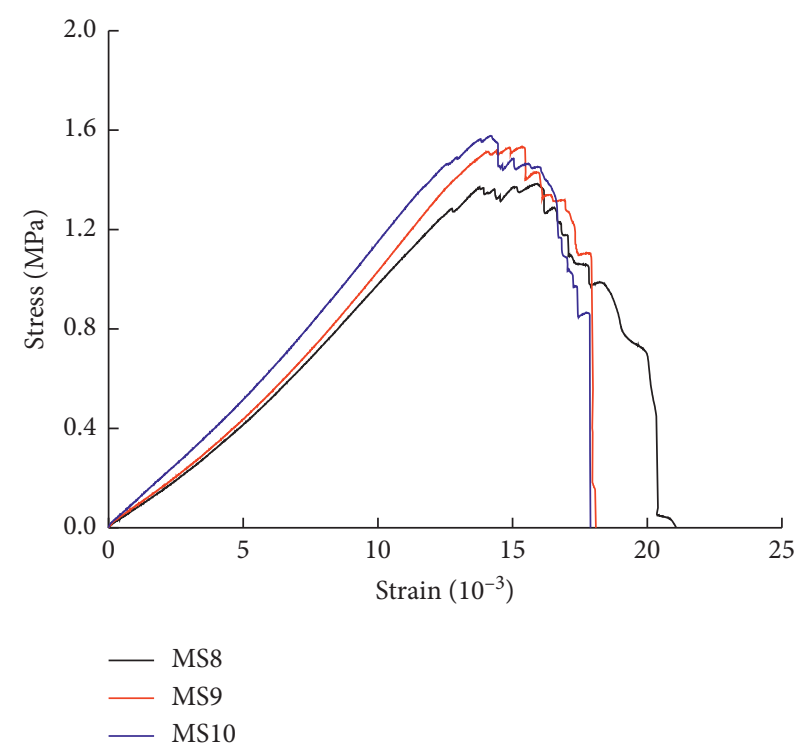

(b)

FIgURE 4: Continued. 

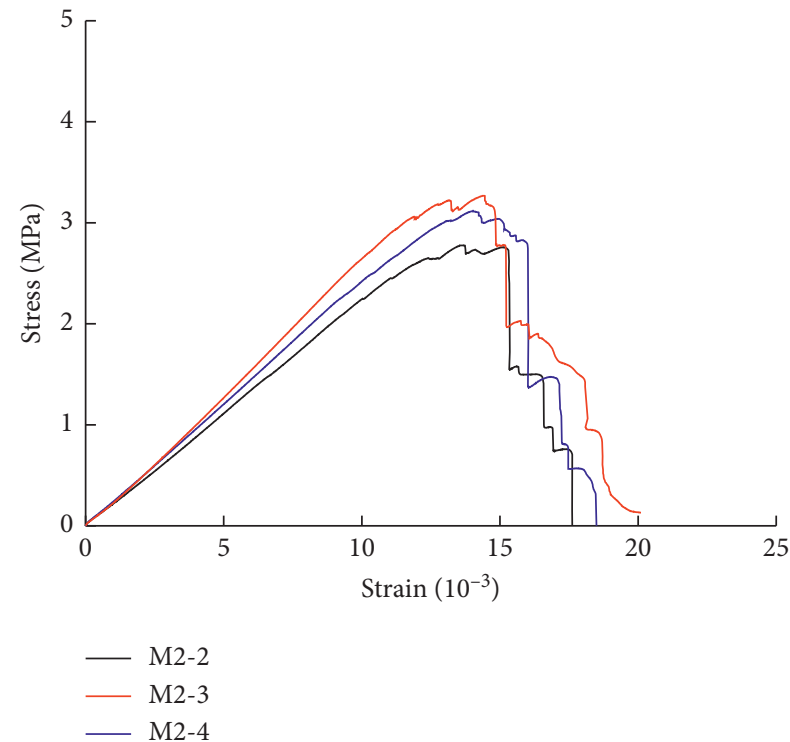

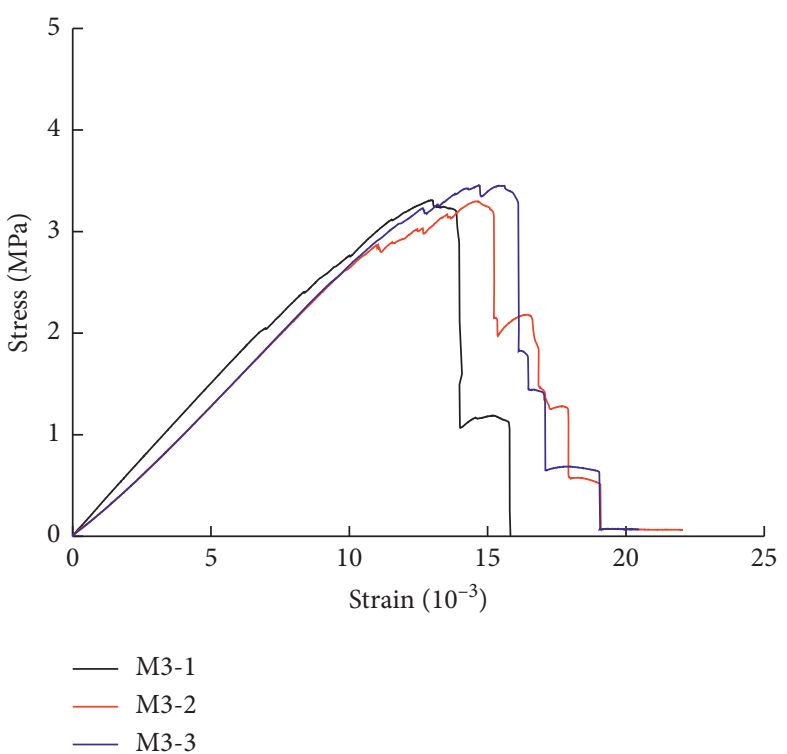

(d)

(c)

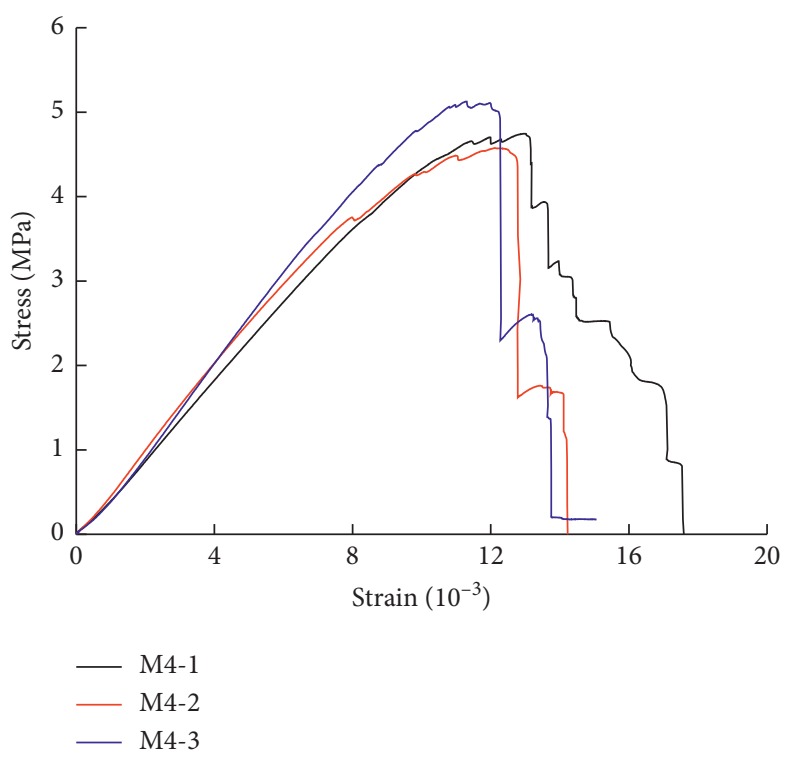

(e)

Figure 4: Uniaxial compression stress-strain curves of raw coal samples (a) and briquette coal samples (b-e) with different shares of cement content: (b) group (I) 0\%; (c) group II, 5\%; (d) group III, 10\%; (e) group IV, $20 \%$.

groups II and III are approximately the same, and their elastic and plastic stages are more obvious. After stresses in M2-2, M2-3, and M2-4 samples reached the peak, their fracture continues for some period, and then a multistep drop will occur. The M3-1, M3-2, and M3-3 briquette coal samples also showed a step-like drop phenomenon after reaching the peak, showing the characteristics of brittle failure, as shown in Figures 4(c) and 4(d). In the uniaxial compression tests of briquette coal samples from group IV, the elastic and plastic stages were still prominent. The M4-1, M4-2, and M4-3 briquette coal samples exhibited a stepped stress drop after the peak and obvious brittle failure characteristics. The above analysis shows that strains in coal briquette samples under uniaxial compression were larger than in raw coal samples. The stress drop was mostly stepped. At zero cement content, the uniaxial compression test resulted in plastic failure. As the cement content was increased, the fracture of briquette coal samples started to show the characteristic of brittle failure.

The comparative analysis of stress-strain curves of MS9, M2-3, M3-1, and M4-3 briquette coal samples (Figure 5) revealed the following specific features. At the plastic stage, the cement content's growth increased the stress-strain curve slope and gradually decreased the axial strain corresponding to the peak stress. At the final failure stage, with an increase in cement content, the strain-softening briquette 


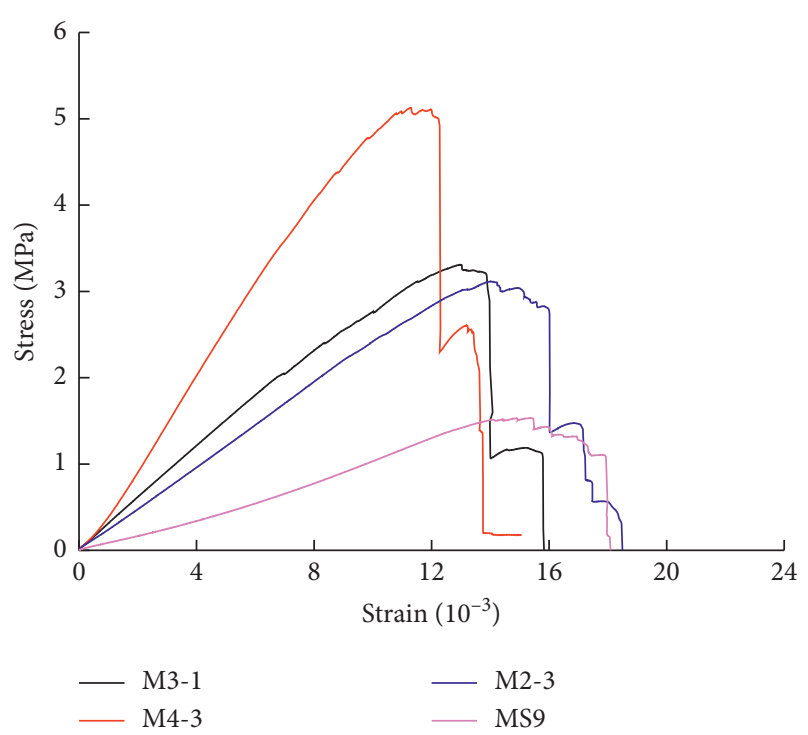

FIGURE 5: Comparison of stress-strain curves of several types of briquette coal samples under uniaxial compression.

coal sample was replaced by the stress drop, which became quite pronounced. Plastic deformation was followed by brittle failure, which behavior was similar to that of raw coal samples.

It can be seen from Figure 6 that, as the cement content increased, the elastic modulus of the briquette gradually rose, and Poisson's ratio gradually dropped. This may be due to the hydration reaction of the cement added to the briquette when it was mixed with water, which increased the sample's strength and elastic modulus but decreased its Poisson's ratio. The ratios between the average elastic moduli briquette coal samples with $0,5,10$, and $20 \%$ cement contents to that of the raw coal were 8.16, 17.01, 19.05, and $33.33 \%$, respectively. In contrast, their average Poisson's ratios divided by that of the raw coal equaled to 142.11, 84.21, 52.63 , and $57.90 \%$, respectively. It can be seen that the cement content in the briquette coal sample has a stronger effect on Poisson's ratios of briquette coal samples and a weaker effect on their elastic moduli.

3.2. Strength Characteristics. The uniaxial compressive strength of briquette coal samples is related to their cement content, as shown in Figure 7. It can be seen that the uniaxial compressive and peak strengths of briquette coal samples both increase with cement content. The uniaxial compressive strength of briquette coal samples with cement contents of $0,5,10$, and $20 \%$ accounts for $34.56,70.28,77.19$, and $111.06 \%$ of the average value of raw coal samples.

3.3. The AE Characteristics. The coal sample's damage by external loading manifests itself by a series of AE signals characterized by several AE parameters during the process of coal deformation and failure. In this paper, the AE amplitude $\left(A, \sum A\right)$, count $\left(N, \sum N\right)$, and energy $\left(E, \sum E\right)$ are used to analyze the AE signals of raw coal and briquette coal samples with different cement contents under uniaxial compression.
The AE amplitude $\left(A, \sum A\right)$ is the maximum amplitude of the voltage signal released by the coal sample during the load damage event; The $\mathrm{AE}$ count $\left(N, \sum N\right)$ reflects the frequency of the $\mathrm{AE}$ event; the $\mathrm{AE}$ energy $\left(E, \sum E\right)$ is the relative energy released by the $\mathrm{AE}$ event. Thus, $\mathrm{AE}$ amplitude, count, and energy together reflect the intensity and frequency of $\mathrm{AE}$ events during the coal sample's deformation and fracture.

Figures 8-13 show the monitoring results of the AE characteristic parameters (amplitude, count, and energy) in the process of uniaxial compression of raw coal and briquette coal samples with different cement contents. To differentiate the many results obtained, each figure depicts the monitoring results of a typical $\mathrm{AE}$ characteristic parameter in each group of coal samples.

It can be seen in Figure 8 that the amplitude, count, and energy of the AE signal of the MB1 raw coal sample at the compaction and elastic stages is relatively low. This is because the intact hard coal sample cannot form new microcracks under relatively low stress. Still, the originally open structural surfaces or original microcracks in the rock are closed. A relative slippage will occur between closing cracks, and the occlusion failure between the structural surfaces will also produce AE events with relatively low energy. At this stage, the accumulated value of the amplitude, count, and energy of the AE signal and its duration can be approximated by a linear relationship.

When the stress continues to increase and enters the plastic (yield) stage, the coal sample exhibits the internal structural damage development; microcracks in the coal sample begin to appear, and the $\mathrm{AE}$ events are activated at this stage. The count and energy of AE begin to increase, the instantaneous ring count reaches $6.35 \times 10^{3}$ times/s, and the instantaneous energy reaches $2.38 \times 10^{4} \mathrm{mv} \cdot \mathrm{ms}$, which can be used as a precursor to determining the fracture of coal samples. When the coal sample's stress approaches the peak strength that the coal sample can withstand, the latter enters the failure stage, whereas new microcracks are generated in it. Then, the polymerization and penetration occur, and the macrofracture surface is damaged. The AE activity at the failure stage is relatively pronounced, and the instantaneous amplitude, count, and energy of $\mathrm{AE}$ reach the peak values at the failure stage, which are $6.57 \times 10^{3} \mathrm{mv}, 2.62 \times 10^{3} \mathrm{times} / \mathrm{s}$, and $5.58 \times 10^{3} \mathrm{mv} \cdot \mathrm{ms}$, respectively. Subsequently, the coal sample shows the overall sliding along the macrofracture surface. In the sliding process, the circumferential tensile stress is produced by friction, and then a tensile fracture occurs. With an increase in strain, the tensile plane breaks several times, resulting in the stepped drop of stress. Before each stress drop, an AE event with a large amplitude will still occur. In general, the absolute value of the amplitude, count, and energy of AE decreases as the stress drops.

It can be seen in Figure 9 that the AE characteristics of the MS9 briquette coal sample with zero cement content during uniaxial compression are lower than those of the MB1 raw coal sample. The overall AE parameters of the MS9 briquette coal sample are not large, i.e., relatively insignificant. At the initial compaction stage of loading, there is an immediate increase in amplitude, count, and energy. This is because the pores existing between the coal particles within 


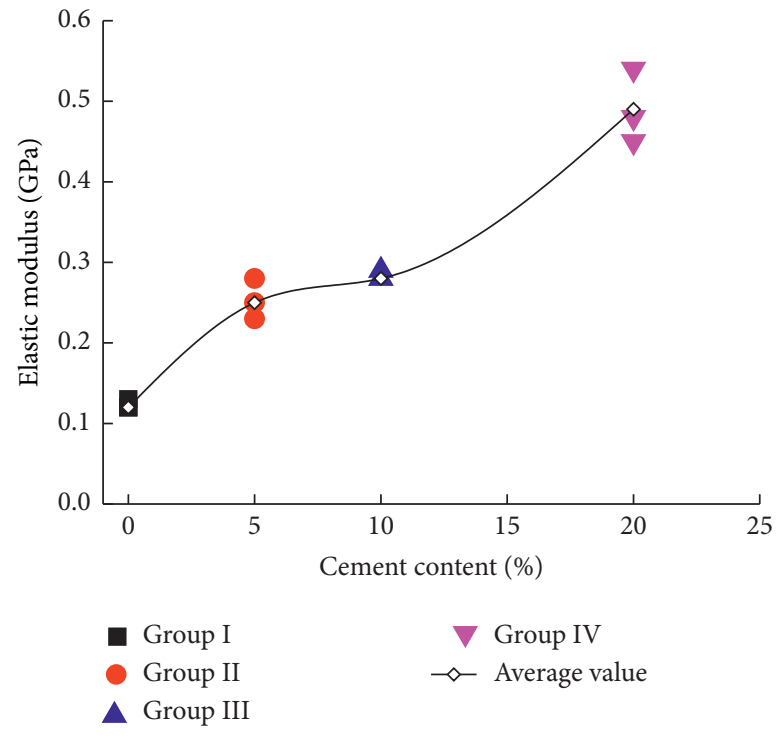

(a)

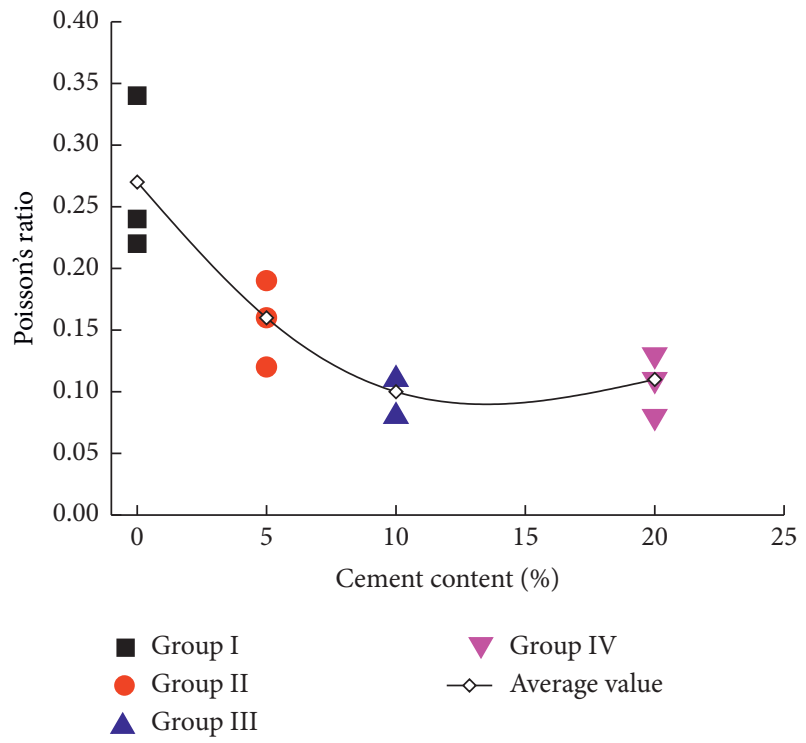

(b)

FIGURE 6: Uniaxial compression deformation parameters of briquette coal samples and cement content: (a) elastic modulus vs. cement content; (b) Poisson's ratio vs. cement content.

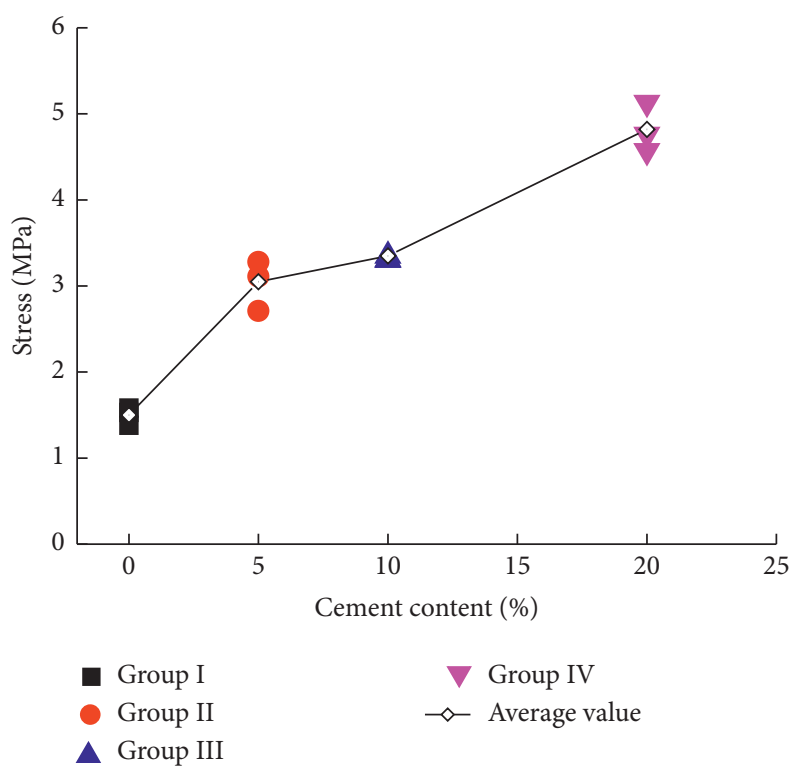

FIGURE 7: Relationship between the compressive strength of briquette coal samples and their cement content.

the briquette coal are closed, and the briquette has been compacted, which results in the $\mathrm{AE}$ amplitude, count, and instantaneous rise in energy. When the stress continues to increase at the elastic stage, a relative slippage occurs between closed cracks. The occlusion failure of the structural surface will also produce an AE event with lower energy. At the elastic phase, the amplitude, count, and energy accumulation value and time of the AE parameters can be approximated by a linear relationship.

When stresses in the briquette coal sample reach the plastic (yield) stage, microcracks appear, and new tensile cracks are generated. The $\mathrm{AE}$ events at this stage are relatively concentrated, and the $\mathrm{AE}$ amplitude, count, and energy reach their upper limits of $2.5 \times 10^{2} \mathrm{mv}, 1.49 \times 10^{2}$ times/s, and $8.32 \times 10^{4} \mathrm{mv} \cdot \mathrm{ms}$, respectively. After the peak stress is reached, a stepped stress drop and an $\mathrm{AE}$ event with considerable accumulated energy are observed. The instantaneous $\mathrm{AE}$ energy value at the failure stage is $3.23 \times 10^{5} \mathrm{mv} \cdot \mathrm{ms}$, which exceeds that at the plastic stage by 3.88 times. It can be seen that the maximum values of $\mathrm{AE}$ energy, amplitude, and count do not necessarily occur simultaneously.

From Figures 10-12, it can be seen that the AE characteristics of M2-3, M3-3, and M4-1 briquette coal samples 


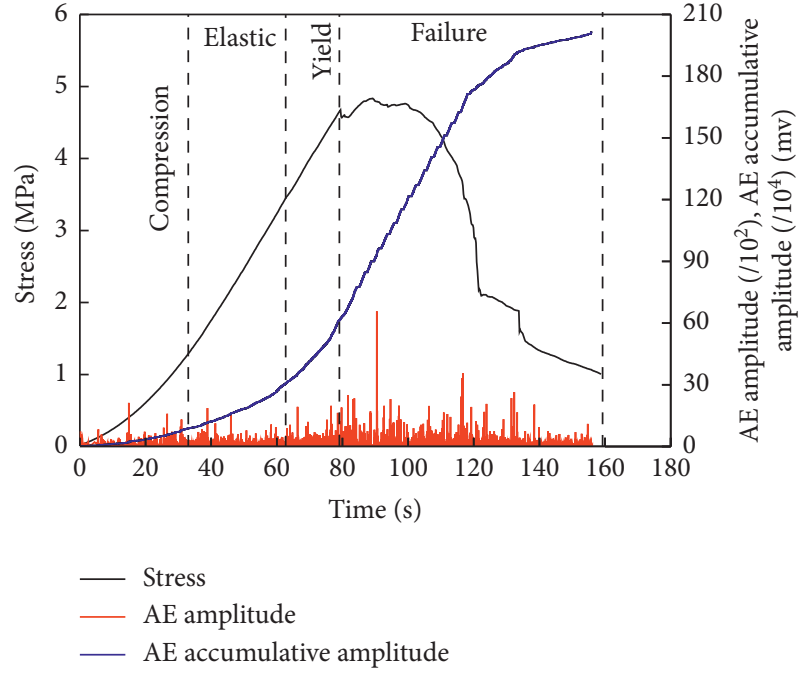

(a)

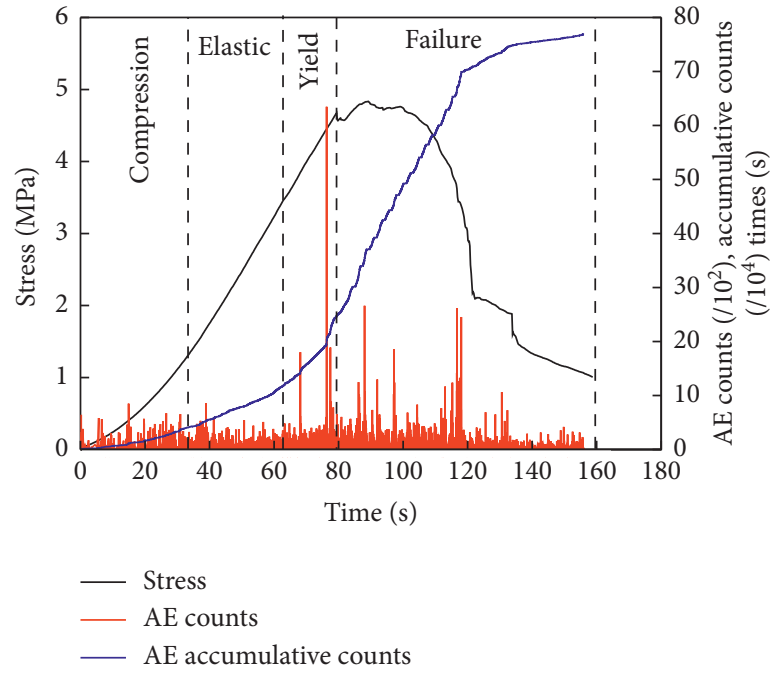

(b)

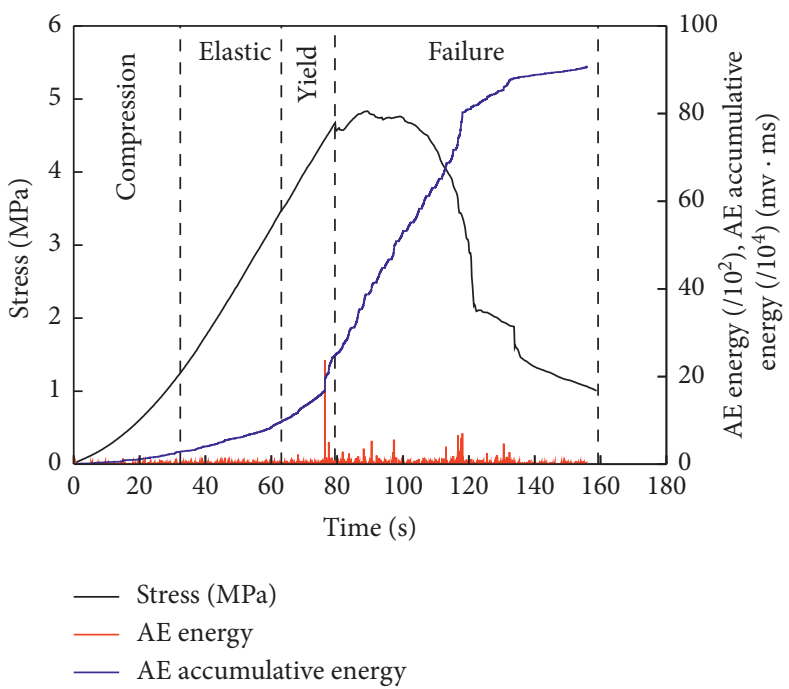

(c)

Figure 8: Monitoring results on AE characteristics of raw coal sample MB1 under uniaxial compression: (a) stress and amplitude; (b) stress and counts; (c) stress and energy.

with a cement content of 5,10 , and $20 \%$ at the compaction and elastic stages are nearly the same. In contrast, the amplitude, count, and energy of their AE signals are relatively small.

When the plastic stage is reached, the coal sample's internal fracture continues to develop, and the AE events get more active. The AE amplitude, count, and energy increase significantly. As seen in Figure 10, the turning point of the cumulative value of the AE amplitude, count, and energy appears at about $97 \%$ of the peak stress, and they sharply increase before the peak. Among them, the instantaneous amplitude, count and energy of the M2-3 briquette coal sample reached $4.22 \times 10^{2} \mathrm{mv}, 2.32 \times 10^{2}$ times $/ \mathrm{s}$, $1.64 \times 10^{3} \mathrm{mv} \cdot \mathrm{ms}$ (Figure 10 ), while the respective parameters of the M3-3 briquette coal sample M3-3 reached $1.27 \times 10^{3} \mathrm{mv}, 21 \mathrm{times} / \mathrm{s}, 1.04 \times 10^{3} \mathrm{mv} \cdot \mathrm{ms}$ (Figure 11 ).
When the sample starts to enter the failure stage, cracks in it form a macrofracture slip surface. The AE events at this stage are more pronounced; the instantaneous amplitude and energy of M2-3 briquette coal samples are $3.95 \times 10^{2} \mathrm{mv}$ and $3.85 \times 10^{2} \mathrm{mv} \cdot \mathrm{ms}$, respectively (Figure 10 ). The instantaneous amplitude and energy of M3-3 AE of the briquette coal sample are $4.70 \times 10^{2} \mathrm{mv}$ and $2.05 \times 10^{3} \mathrm{mv} \cdot \mathrm{ms}$ (Figure 11).

From Figure 12, it can be concluded that the M4-1 briquette coal sample with a $20 \%$ cement content has a significantly lower amplitude, count, and energy of the AE signal during the initial loading compaction and elastic stages. Compared with the AE characteristics of two groups of briquette coal samples with cement contents of $5 \%$ and $10 \%$, its compaction stage is relatively short. This is because the added cement densely fills the pores existing in the coal 


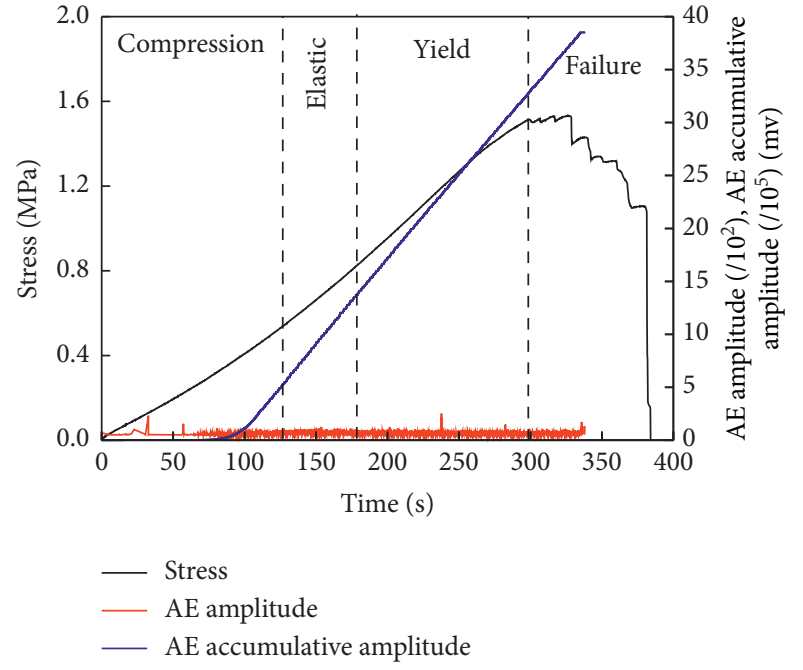

(a)

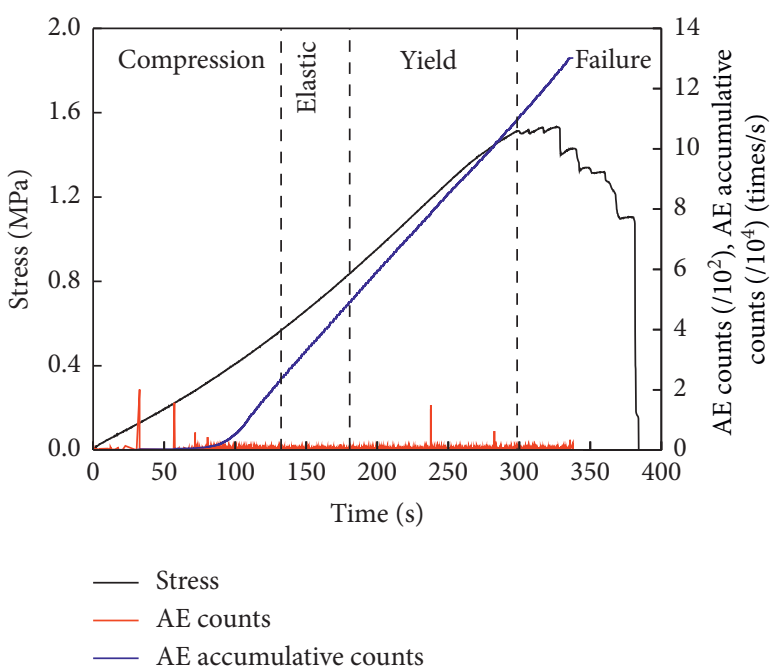

(b)

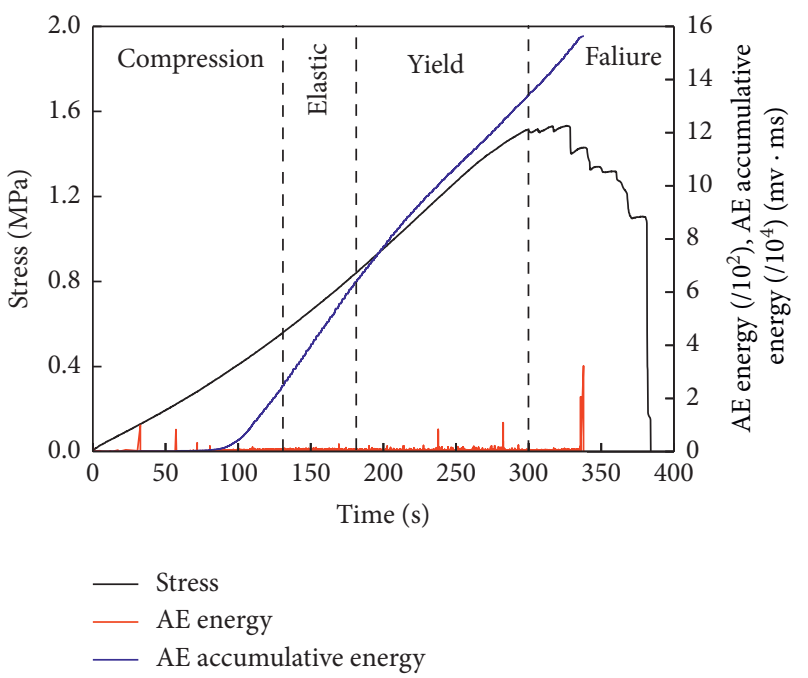

(c)

FIGURE 9: Monitoring results on AE characteristics of briquette coal sample MS9 under uniaxial compression: (a) stress and amplitude; (b) stress and counts; (c) stress and energy.

body after the hydration reaction, reduces the inherent pores and cracks in the coal body, and makes the coal body denser. When the stress value reaches the plastic (yield) stage, microcracks in the coal sample begin to develop, and the coal sample undergoes preliminary damage. $\mathrm{AE}$ events at this stage are relatively dense, and the $\mathrm{AE}$ amplitude, count, and energy permanently increase, the energy rise being the most pronounced. When the loading enters the fracture stage, the instantaneous $\mathrm{AE}$ energy value of the M4-1 briquette coal sample reaches $3.41 \times 10^{3} \mathrm{mv} \cdot \mathrm{ms}$. Subsequently, the stress experiences a stepped drop, and the instantaneous value of the stepped drop energy reaches $1.33 \times 10^{3} \mathrm{mv} \cdot \mathrm{ms}$.

It can be seen in Figures 10-12 that the AE signals are always observed during the deformation and failure process of coal samples with $0,5,10$, and $20 \%$ cement contents under uniaxial compression. The AE amplitude, count, and energy have a good correspondence with the time-stress relationship curve. Still, the AE characteristics of coal samples with various cement contents are different. The maximum values of the amplitude, count, and $\mathrm{AE}$ energy do not appear simultaneously, but there is a good correspondence between these parameters. As the cement content increases, the turning point of the cumulative amplitude and count of $\mathrm{AE}$ is delayed, and the turning point of the cumulative energy is advanced.

It can be deduced from Figure 13 and Table 1 that the $\mathrm{AE}$ cumulative amplitudes of briquette coal samples during uniaxial compression gradually increase with cement 


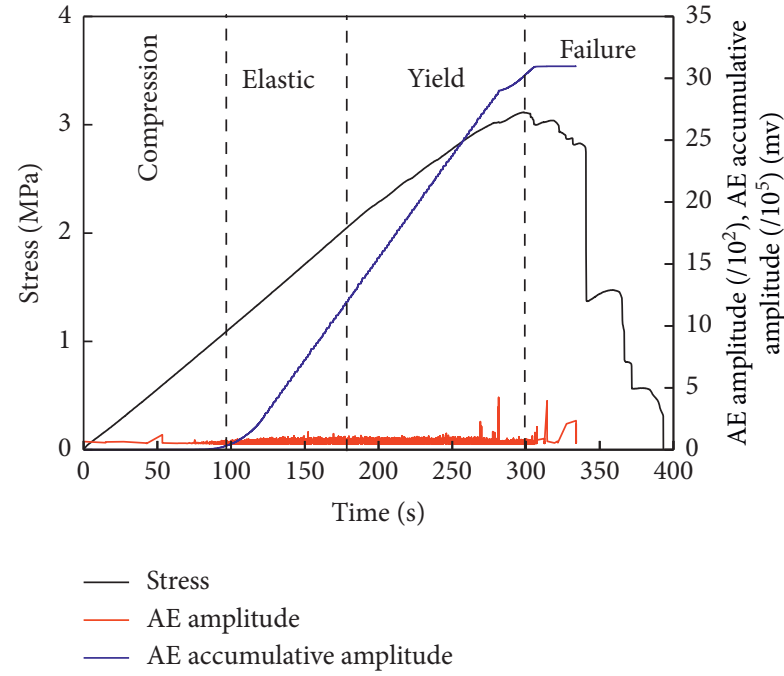

(a)

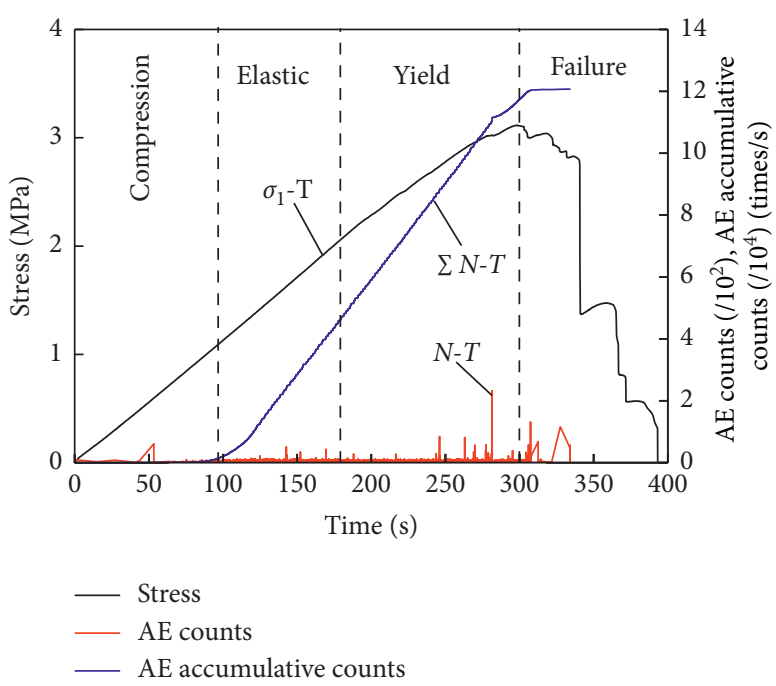

(b)

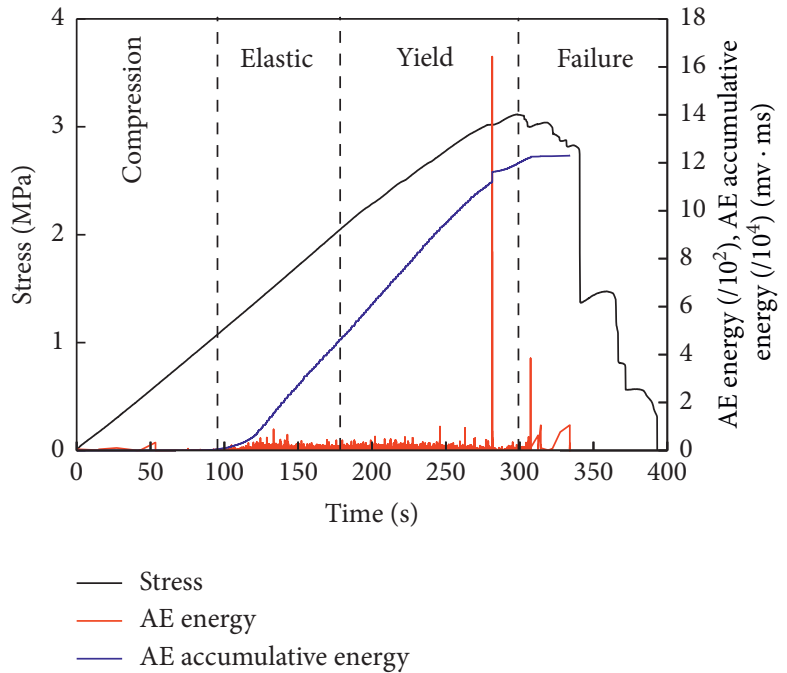

(c)

Figure 10: Monitoring results on AE characteristics of briquette coal sample M2-3 with a cement content of 5\% under uniaxial compression: (a) stress and amplitude; (b) stress and counts; (c) stress and energy.

content and exhibit a gradual saturation. However, these values exceed that of the average raw coal sample $\left(1.54 \times 10^{6} \mathrm{mv}\right)$. The cumulative count of AE increases with the cement content and is gradually saturated. However, it is lower than the respective average value of raw coal samples $\left(7.04 \times 10^{5}\right.$ times/s). The AE cumulative energy shows an increasing linear trend with cement content related to the improved strength of briquette coal samples with cement content. However, these values are lower than those of the average raw coal sample $\left(6.22 \times 10^{5} \mathrm{mv} \cdot \mathrm{ms}\right)$.

\section{Discussion}

Figures 14 and 15 show the damage patterns of the raw coal and briquette coal samples with different cement contents after uniaxial compression. In both types of samples, the final failure after uniaxial compression can be approximately regarded as a splitting failure parallel to the axial direction. When one or several dominant cracks grow, they are first to propagate. When other cracks have not fully developed yet, the entire coal sample will be broken into multiple flaky fragments. But at the same time, there is a shear failure surface in the coal sample; that is to say, the uniaxial compression failure of the coal sample also has a double fracture surface of tensile shear.

4.1. Deformation and Strength Evolution of Coal Samples. Raw coal is heterogeneous due to pores, cracks, and joint development in the coal body, and some parameters, such as the uniaxial compressive strength, are relatively discrete. The uniaxial compression failure of raw coal often appears as a brittle fracture, which manifests as an instantaneous stress drop in MB6 and MB7 coal samples. Sometimes, the stress will drop stepwise, as in MB3 and MB4 samples. 


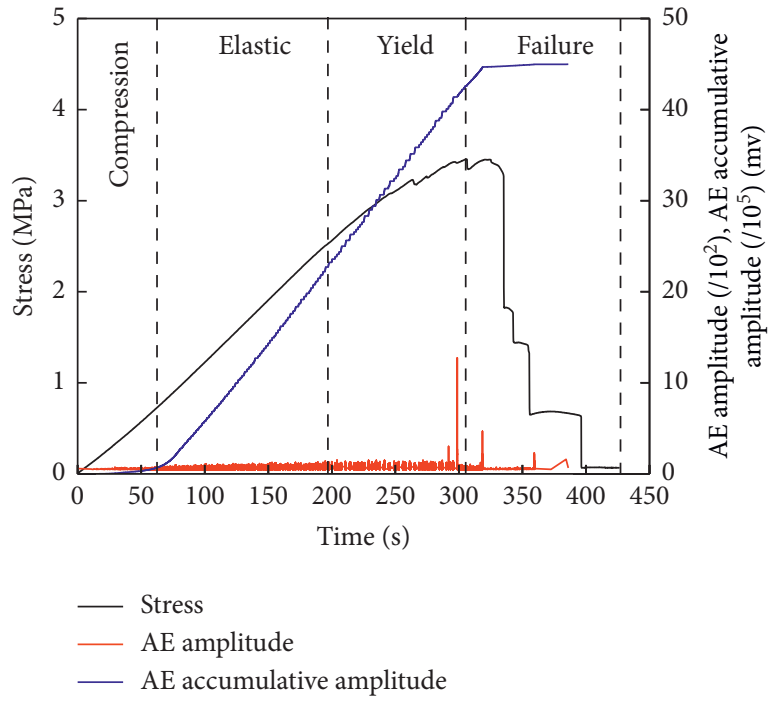

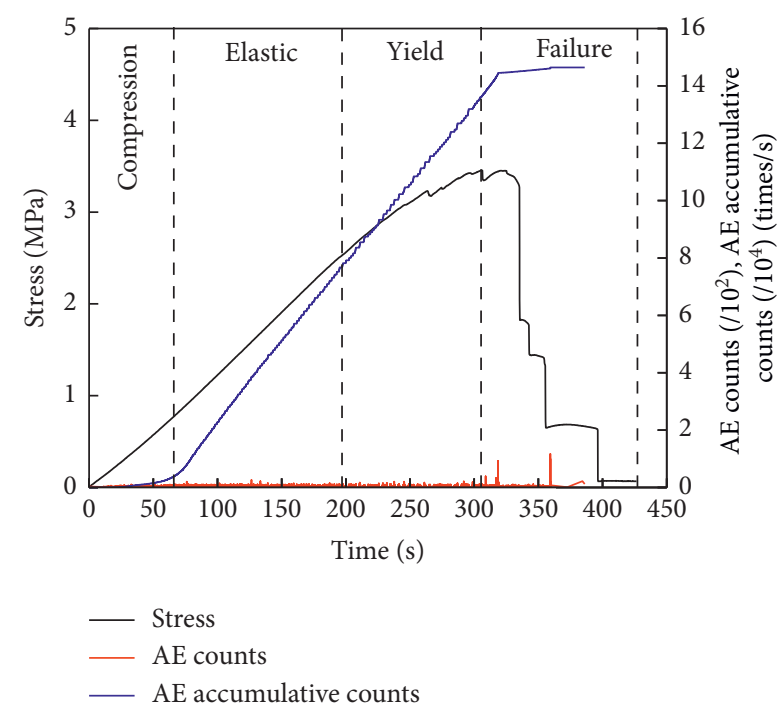

(b)

(a)

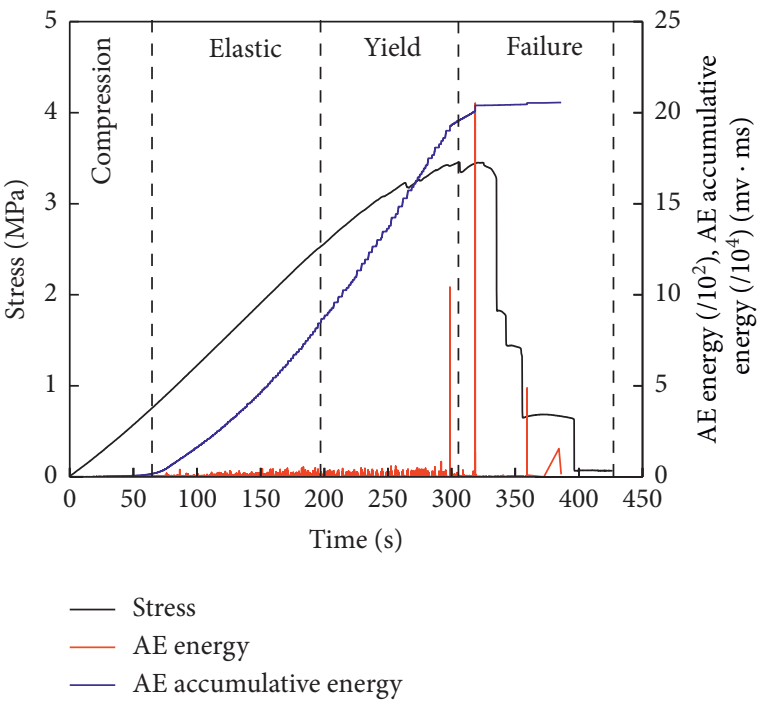

(c)

FIgURE 11: Monitoring results on AE characteristics of briquette coal sample M3-3 with a cement content of $10 \%$ under uniaxial compression: (a) stress and amplitude; (b) stress and counts; (c) stress and energy.

The average value of the raw coal sample's uniaxial compressive strength is $4.34 \mathrm{MPa}$, while those of briquette coal samples with cement contents of $0,5,10$, and $20 \%$ are $1.503 .05,3.35$, and $4.82 \mathrm{MPa}$, respectively. It can be found that the uniaxial compressive strength of briquette coal samples increases with cement content. The average value of the uniaxial compressive strength of briquette coal samples with $20 \%$ cement content is closest to the average value of raw coal samples.

Under uniaxial compression, the elastic modulus of briquette coal increases with cement content. The average value of the elastic modulus of raw coal samples is $1.47 \mathrm{GPa}$, while that of briquette coal samples with a $20 \%$ cement content is $0.49 \mathrm{GPa}$, which is one-third of the former value. This is because, during the uniaxial compression of the briquette coal sample, a relatively large axial deformation is generated. In the case of the briquette coal sample with a $20 \%$ cement content, its average value is $1.61 \mathrm{~mm}$, which exceeds the respective average value raw coal $(0.7 \mathrm{~mm})$ by 2.3 times. Poisson's ratio of briquette coal samples under uniaxial compression decreases with cement content. The respective average values of briquette coal samples with cement contents of $0,5,10$, and $20 \%$ are $0.27,0.16,0.1$, and 0.11 , exceeding those of raw coal samples by $1.42,0.84,0.53$, and 0.58 times, respectively. Generally speaking, the cement content in briquette coal samples has little effect on Poisson's ratio.

Therefore, in terms of uniaxial compressive strength and elastic modulus, the mechanical properties of briquette coal samples with a $20 \%$ cement content are closest to those of raw coal samples. 

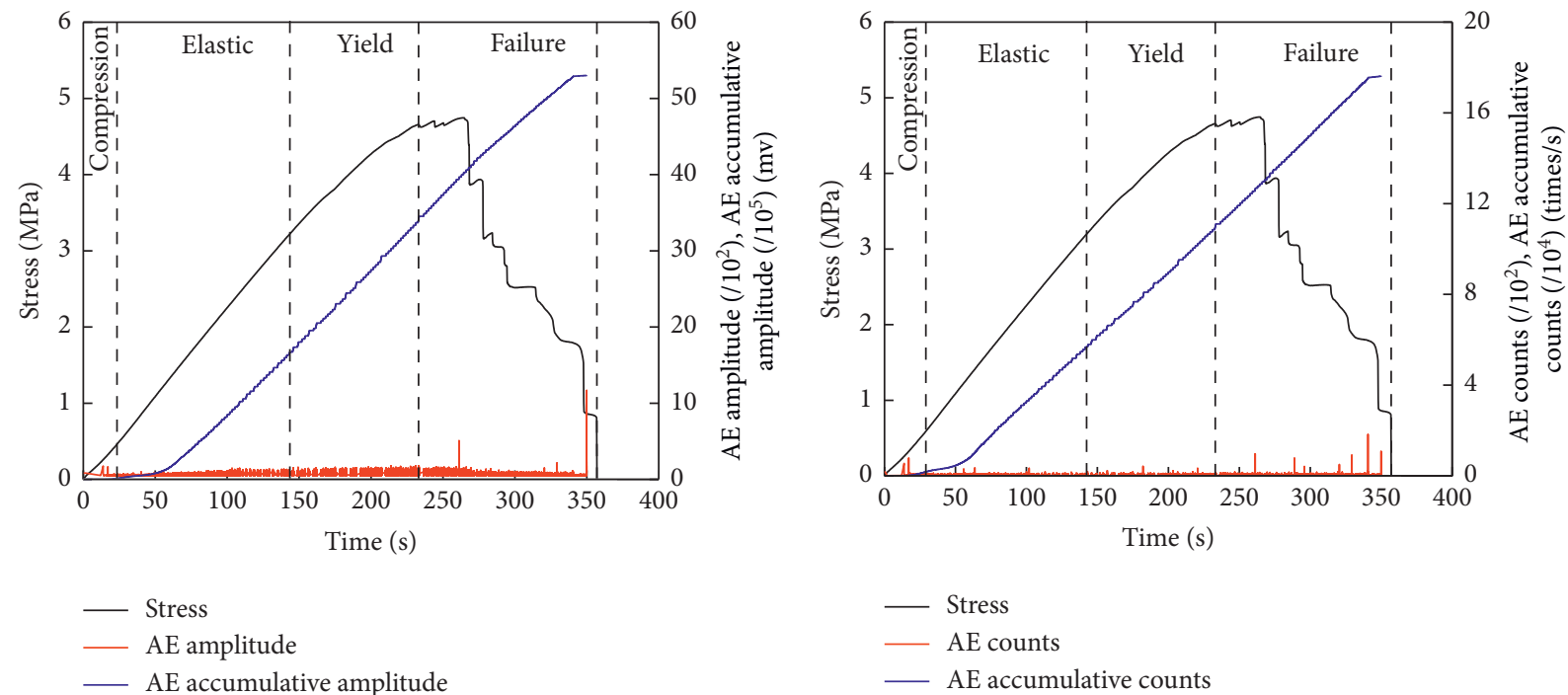

(a)

(b)

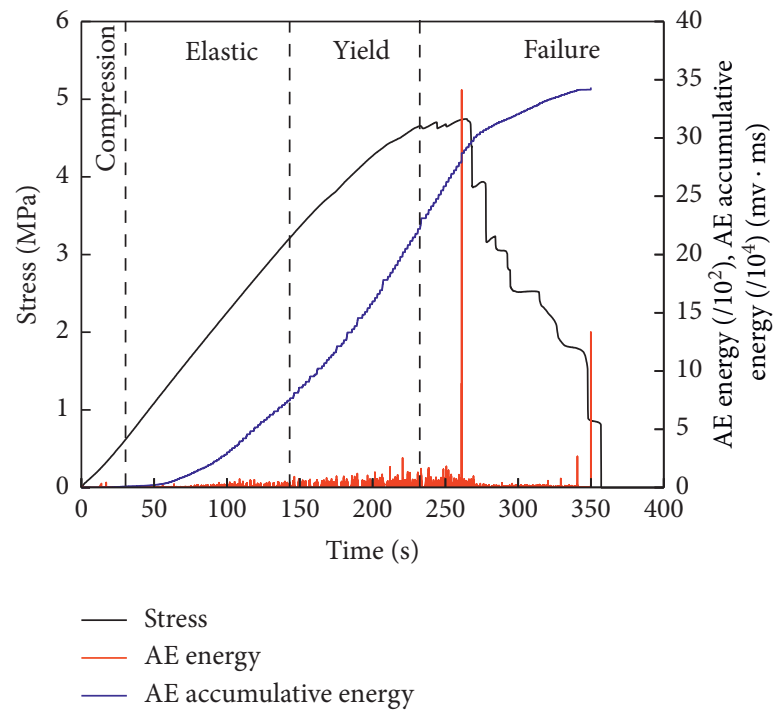

(c)

Figure 12: Monitoring results on AE characteristics of briquette coal sample M4-1 with a cement content of $20 \%$ under uniaxial compression: (a) stress and amplitude; (b) stress and counts; (c) stress and energy.

4.2. Characteristic AE Parameters of Coal Samples. During the AE monitoring of uniaxially compressed MB1 raw coal samples1, at the initial compaction and elastic stages, the amplitude, count, and energy of the AE signal were recorded with a low number of events. During the plastic (yield) stage, the amplitude, count, and AE energy increase significantly. This is related to the formation of new microcracks in the coal body, rupture, and the development of macrofractures. At the beginning of the failure stage, the amplitude, count, and energy of the AE signal reach their peak intensities, and each stress drop is accompanied by a rise of the amplitude, count, and energy of the AE signal.

The amplitude, count, and energy of the AE parameters of briquette coal samples are less pronounced than those of raw coal samples related to the briquette coal sample structure. For example, the briquette coal sample compactness and elastic modulus are relatively low. In briquette samples with cement contents of $0,5,10$, and $20 \%$, the amplitude, count, and energy of AE signals are relatively low in the compression and elastic stages. However, when the plastic stage is reached, microcracks continuously develop in the coal body. At this time, the amplitude, count, and energy of the AE signal become active and reach the peak points near the yield strength value. The characteristics of the monitored $\mathrm{AE}$ signal indicate that the maximum values of AE energy, amplitude, and count do not necessarily occur synchronously.

The AE signal's cumulative energy under the uniaxial compression of briquette coal samples shows a linear increase with cement content. The accumulative amplitude and count of the AE signal also increase with the cement content, showing the characteristics of gradual saturation. 


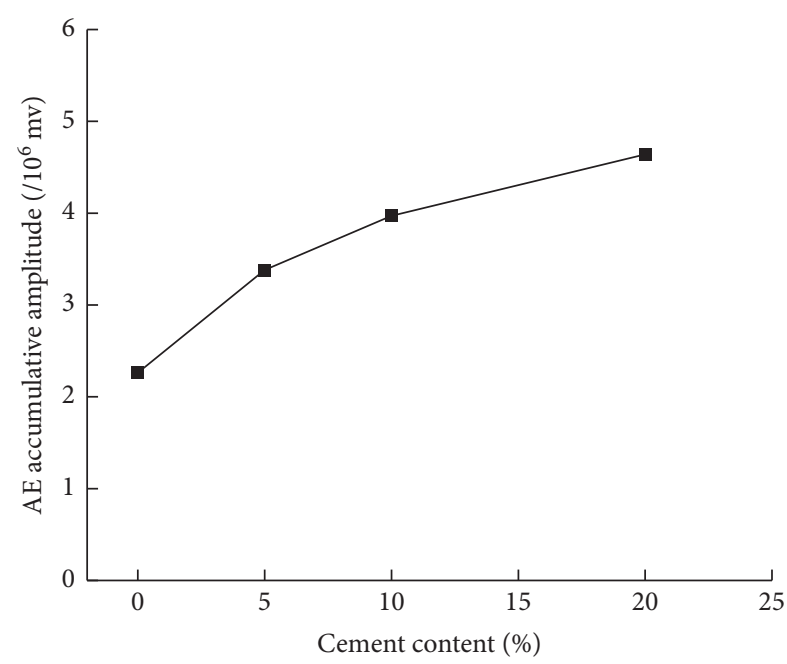

(a)

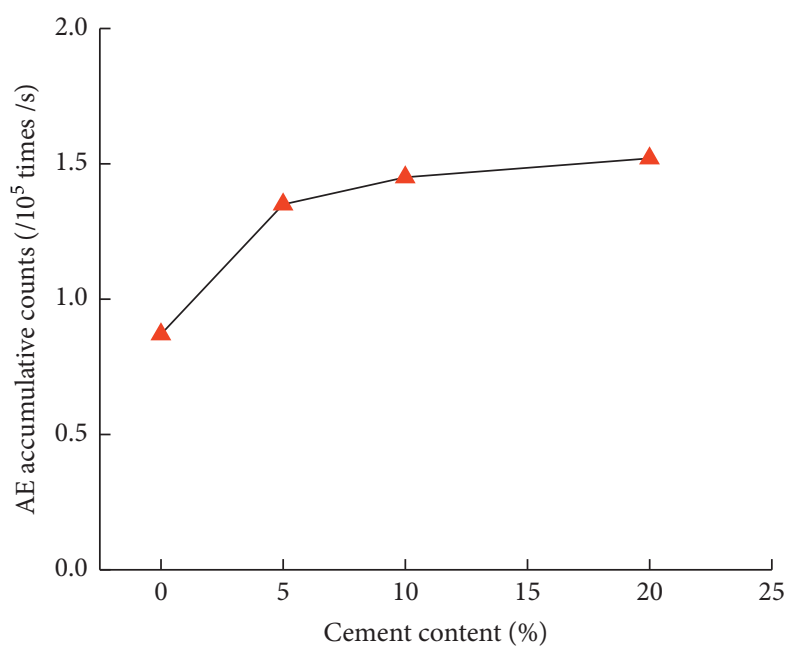

(b)

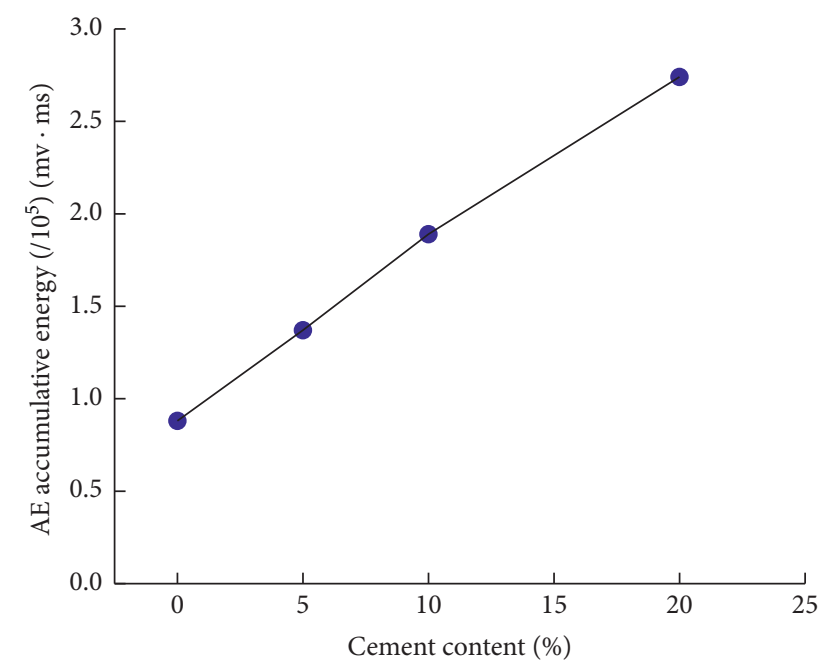

(c)

FIGURE 13: Correlation between AE parameters and cement content of briquette coal samples: (a) accumulative amplitude vs. cement content; (b) accumulative count vs. cement content; (c) accumulative energy and cement content.

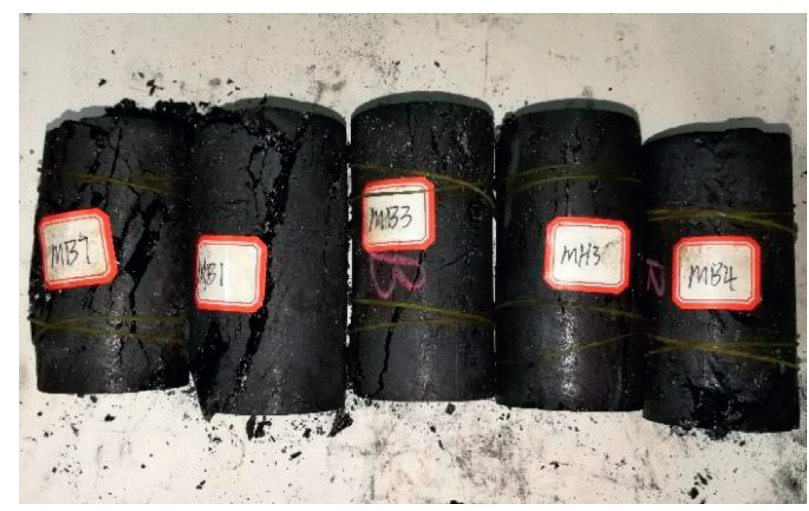

Figure 14: Raw coal samples failed under uniaxial compression.

According to the monitored AE signals of briquette coal samples, as listed in Table 1, the average values of the $\mathrm{AE}$ cumulative amplitude, count, and energy of the briquette coal sample with a $20 \%$ cement content are very close to those of the raw coal sample. The cumulative count and cumulative energy values are $1.52 \times 10^{5}$ times/s and 


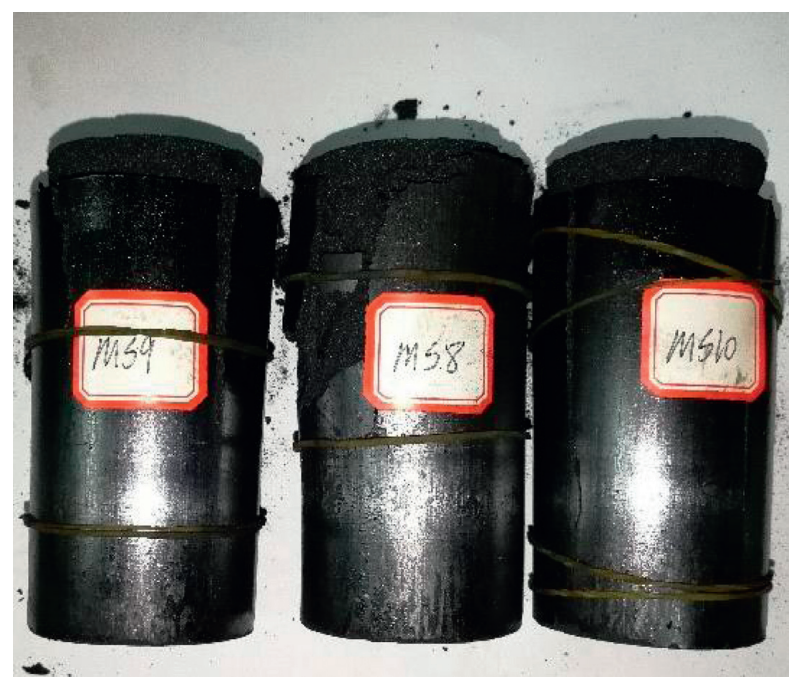

(a)

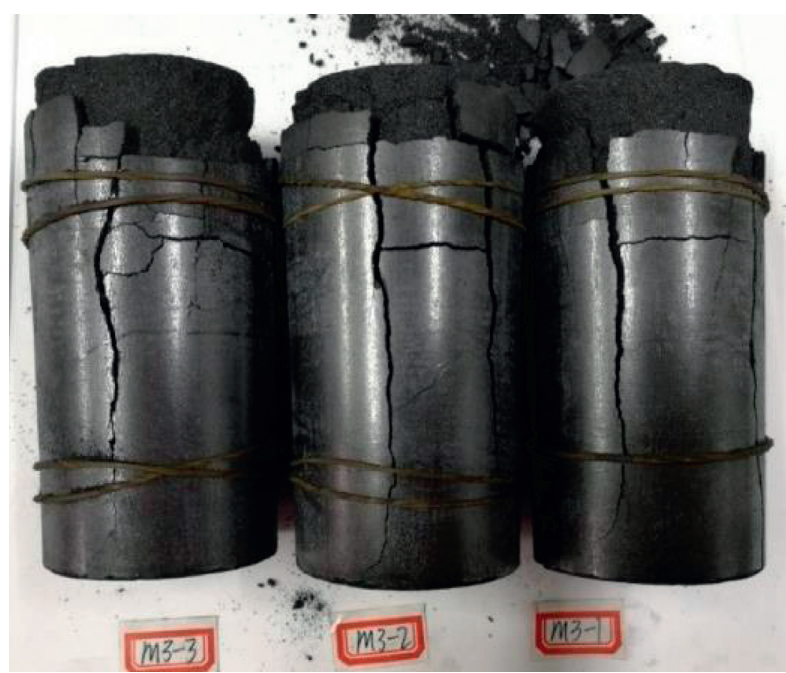

(c)

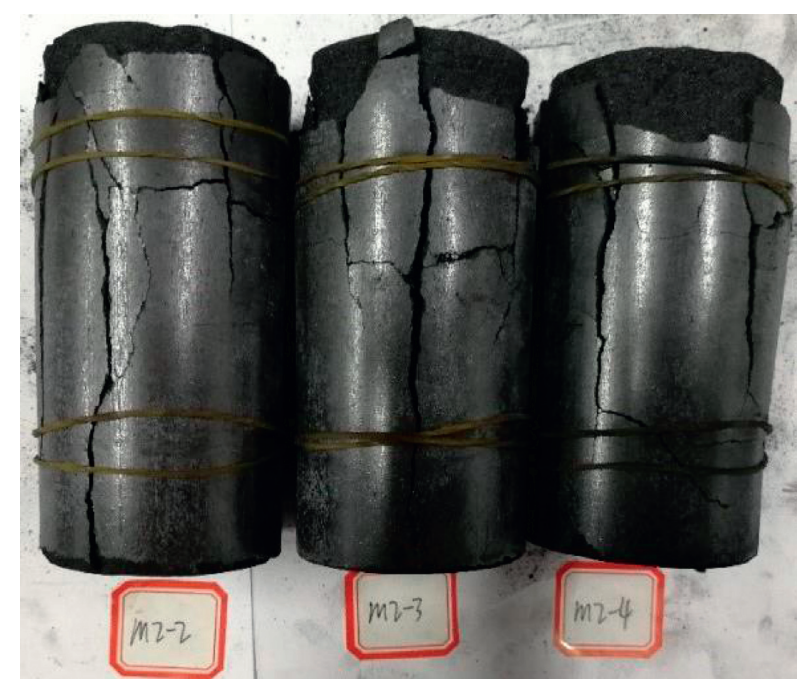

(b)

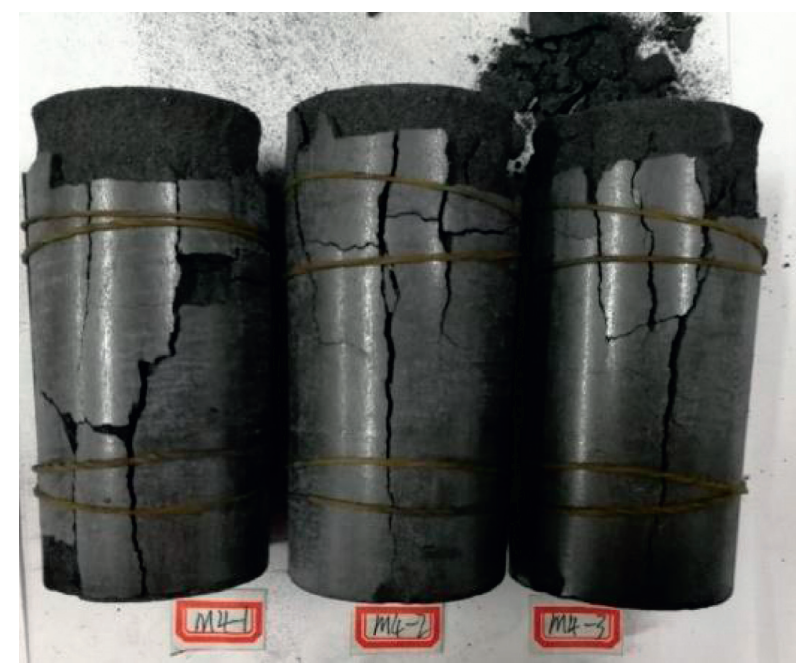

(d)

FIGURE 15: Examples of the uniaxial compression failure of briquette coal samples with different cement contents: (a) $0 \%$; (b) $5 \%$; (c) $10 \%$; (d) $20 \%$.

$2.74 \times 10^{5} \mathrm{mv} \cdot \mathrm{ms}$, which are very close to those of raw coal samples. Therefore, the mechanical properties and AE signals of briquette coal samples with a cement content of $20 \%$ are closer to those of raw coal samples.

\section{Conclusions}

Deformation, strength, and AE characteristics of raw coal and briquette coal samples with different cement contents obtained during the uniaxial compression tests were analyzed and discussed in detail. The main conclusions are as follows:

(1) The process of uniaxial compression of raw coal and briquette coal samples with different cement contents can be subdivided into compaction, elastic, plastic (yield), and failure stages. With an increase in cement content during the uniaxial compression of briquette coal samples, the elastic and plastic stages become more obvious, the stress-strain curve gradually becomes steeper, the peak strength is gradually increased, while the axial deformation gradually drops. The stress drop after the peak is quite pronounced, and the deformation of the briquette coal sample gradually changes from plastic to brittle failure.

(2) With an increase in cement content from 0 to $20 \%$ in briquette coal samples, their uniaxial compressive strength and elastic modulus are increased, while Poisson's ratio drops. However, comparing the uniaxial compressive strength, elastic modulus, and Poisson's ratio of briquette coal samples with different cement contents to those of raw coal samples, it was found that cement content has a greater effect on the uniaxial compressive strength and elastic modulus of briquette coal samples, and a smaller effect on their Poisson's ratio. This is because 
cement's hydration reaction will change the structure of the briquette coal body and then influence its mechanical properties and AE parameters.

(3) The uniaxial compression of raw coal and briquette coal samples with different cement contents is always accompanied by AE signals. However, in briquette coal samples, the amplitude, count, and energy of the AE signal are relatively small. There is no obvious manifestation of the AE events in raw coal samples. There is a good correspondence between the amplitude, count, and energy of raw coal and briquette coal samples with different cement contents and stress evolution curves. However, the maximum values of the amplitude, count, and energy of the AE signal do not necessarily occur simultaneously.

(4) The study of the uniaxial compressive strength and AE characteristics of raw coal and briquette coal samples with different cement contents revealed that the cumulative amplitude, count, and energy of the mechanical parameters and AE signals of briquette coal samples with a $20 \%$ cement content under uniaxial compression are closest to those of raw coal samples.

\section{Nomenclature}

Rc: Uniaxial compressive strength, $\mathrm{MPa}$

$E_{\mathrm{T}}$ : Elastic modulus, GPa

$\mu$ : Poisson ratio

$\sum A$ : AE accumulative amplitude, $\mathrm{mv}$

$\sum N$ : AE accumulative counts, times/s

$\sum E:$ AE accumulative energy, $\mathrm{mv} \cdot \mathrm{ms}$.

\section{Data Availability}

The data used to support the findings of this study are available from the corresponding author upon request.

\section{Conflicts of Interest}

The authors declare no conflicts of interest regarding the publication of this paper.

\section{Acknowledgments}

This research was financially supported by the National Natural Science Foundation of China (51674102 and 51874121), Key Scientific and Technological Research Plan of Henan Province, China (182102310002), and the funding for Special Research Funds for Colleges and University in Henan Province, China (NSFRF180104).

\section{References}

[1] F.-h. An, Y.-p. Cheng, L. Wang, and W. Li, "A numerical model for outburst including the effect of adsorbed gas on coal deformation and mechanical properties," Computers and Geotechnics, vol. 54, no. 10, pp. 222-231, 2013.

[2] F. Du and K. Wang, "Unstable failure of gas-bearing coal-rock combination bodies: insights from physical experiments and numerical simulations," Process Safety and Environmental Protection, vol. 129, no. 9, pp. 264-279, 2019.

[3] K. Wang and F. Du, "Coal-gas compound dynamic disasters in China: a review," Process Safety and Environmental Protection, vol. 133, no. 1, pp. 1-17, 2020.

[4] F. B. Yu, Coal Mine Gas Disaster Prevention and Utilization Technical Manual, China Coal Industry Publishing House, Beijing, China, 2005.

[5] J. Sobczyk, "The influence of sorption processes on gas stresses leading to the coal and gas outburst in the laboratory conditions," Fuel, vol. 90, no. 3, pp. 1018-1023, 2011.

[6] T. Backers, S. Stanchits, and G. Dresen, "Tensile fracture propagation and acoustic emission activity in sandstone: the effect of loading rate," International Journal of Rock Mechanics and Mining Sciences, vol. 42, no. 7-8, pp. 1094-1101, 2005.

[7] V. Vishal, P. G. Ranjith, and T. N. Singh, "An experimental investigation on behaviour of coal under fluid saturation, using acoustic emission," Journal of Natural Gas Science and Engineering, vol. 22, no. 1, pp. 428-436, 2015.

[8] S. D. Butt, P. K. Frempong, C. Mukherjee, and J. Upshall, "Characterization of the permeability and acoustic properties of an outburst-prone sandstone," Journal of Applied Geophysics, vol. 58, no. 1, pp. 1-12, 2005.

[9] W. K. Zietlow and J. F. Labuz, "Measurement of the intrinsic process zone in rock using acoustic emission," International Journal of Rock Mechanics and Mining Sciences, vol. 35, no. 3, pp. 291-299, 1998.

[10] M. Seto, H. Sato, M. Sato, and M. Kohno, "Hypocenter distributions of AE in coal under uniaxial compression," Journal of the Mining and Metallurgical Institute of Japan, vol. 104, no. 1201, pp. 163-168, 1988.

[11] V. A. Mansurov, "Acoustic emission from failing rock behaviour," Rock Mechanics and Rock Engineering, vol. 27, no. 3, pp. 173-182, 1994.

[12] V. L. Shkuratnik, Y. L. Filimonov, and S. V. Kuchurin, "Experimental investigations into acoustic emission in coal samples under uniaxial loading," Journal of Mining Science, vol. 40, no. 5, pp. 458-464, 2004.

[13] E.-Y Wang, X.-Q He, Z. -T Liu, and Z. -H Li, "Study on frequency spectrum characteristics of acoustic emission in coal or rock deformation and fracture," Journal of China Coal Society, vol. 29, no. 3, pp. 289-292, 2004.

[14] Y.-J Yang, S.-J Chen, and G.-D Han, "Experimental on acoustic during compression rupture procedure of coal sample," Journal of China Coal Society, vol. 31, no. 5, pp. $362-365,2006$.

[15] S.-G Cao, Y.-B Liu, and L. -Q Zhang, "Experimental on acoustic of outburst-hazardous coal under uniaxial compression and creep," Journal of China Coal Society, vol. 32, no. 12, pp. 1264-1268, 2007.

[16] P. G. Ranjith, D. Jasinge, S. K. Choi, M. Mehic, and B. Shannon, "The effect of $\mathrm{CO}_{2}$ saturation on mechanical properties of Australian black coal using acoustic emission," Fuel, vol. 89, no. 8, pp. 2110-2117, 2010.

[17] C.-D Su, B. H. Guo, and X. Tang, "Research on acoustic emission characteristics of Zhangcun coal samples in two sizes in two sizes subject to uniaxial compression," Journal of China Coal Society, vol. 38pp. 12-18, sup1, 2013.

[18] B. -X Huang and J. -W Liu, "The effect of loading rate on the behavior of samples composed of coal and rock," International Journal of Rock Mechanics and Mining Sciences, vol. 61, no. 7, pp. 23-30, 2013. 
[19] M. S. A. Perera, A. S. Ranathunge, and P. G. Ranjith, "Effect of coal rank on various fluid saturations creating mechanical property alterations using Australian coals," Energies, vol. 9, no. 6 , pp. 1-15, 2016.

[20] G.-W Dong and Y.-H Zou, "Novel study of waveguide propagation rules of coal rock $\mathrm{AE}$ signal: effects of waveguide size and installation method on the propagation rules of coal rock AE signal," Sustainability, vol. 9, no. 7, 1209 pages, 2017.

[21] D. Jasinge, P. G. Ranjith, and S. K. Choi, "Development of a reconstituted brown coal material using cement as a binder," Environmental Earth Sciences, vol. 64, no. 3, pp. 631-641, 2011.

[22] D. Jasinge, P. G. Ranjith, S. K. Choi, J. Kodikara, M. Arthur, and $\mathrm{H}$. Li, "Mechanical properties of reconstituted Australian black coal," Journal of Geotechnical and Geoenvironmental Engineering, vol. 135, no. 7, pp. 980-985, 2009.

[23] H.-B Zhao, T. Wang, H. Zhang, and Z.-Q Wei, "Comparison of local load influence on crack evolution of coal and briquette coal sample," Advances in Civil Engineering, vol. 2018, p. 12, Article ID 1790785, 2018

[24] G. Z. Yin, D. K. Wang, D. M. Zhang, and W. Z. Wang, "Test analysis of deformation characteristics and compressive strengths of two types of coal specimens containing gas," Chinese Journal of Rock Mechanics and Engineering, vol. 28, no. 2, pp. 410-417, 2009.

[25] D. Jasinge, P. G. Ranjith, X. Choi, and J. Fernando, "Investigation of the influence of coal swelling on permeability characteristics using natural brown coal and reconstituted brown coal specimens," Energy, vol. 39, no. 1, pp. 303-309, 2012.

[26] The Professional Standards Compilation Group Of People's Republic of China, GT/T25217.2-2010. Methods for test, monitoring and prevention of rock burst-Part2: Classification and Laboratory Test Method on Bursting Liability of Coal, Standards Press of China, Beijing, China, 2010.

[27] H.-X. Lin and C.-Z. Du, "Experimental research on the quasitriaxial hydraulic fracturing of coal," Journal of China Coal Society, vol. 36, no. 11, pp. 1801-1805, 2011.

[28] M.-J Jiang, Y. Xiao, Y.-G. Sun, and X.-F. Wu, "Experimental investigation on micromechanical model of cement-bonded particles," Rock and Soil Mechanics, vol. 33, no. 5, pp. 12931300, 2012. 